\title{
Adult Alveolar Soft Part Sarcoma
}

National Cancer Institute

\section{Source}

National Cancer Institute. Adult Alveolar Soft Part Sarcoma. NCI Thesaurus. Code C7943.

An alveolar soft part sarcoma occurring in adults. The most common site of involvement is the extremity, particularly the deep soft tissues of the thigh. 